HORTSCIENCE 27(11):1198-1200. 1992.

\title{
Role of Sucrose in Bud Development and Vase Life of Cut Liatris spicata (L.) Willd.
}

\author{
Susan S. Han \\ Department of Plant and Soil Sciences, University of Massachusetts, \\ Amherst, MA 01003 \\ Additional index words. pulsing, leaf blackening
}

\begin{abstract}
Sucrose addition to the vase solution improved the postharvest qualities of cut liatris by increasing the length of inflorescences showing color and by prolonging the vase life of the spikes. The main effect of sucrose was on the development and opening of the flower heads with minimal effect on their longevity. Pulsing with concentrations of sucrose $\geq 10 \%$ for 20 hours prolonged the vase life of the spikes. Responses of spikes to the pulsed treatment varied greatly due to the differences in their degree of leafiness, thus limiting its commercial application. A continuous supply of $2.5 \%$ or $5 \%$ sucrose in the vase solution allowed most of the flower heads on the spikes to develop and doubled the vase life of the spikes.
\end{abstract}

Liatris spicata is a cormous perennial that is commercially grown as a cut flower in many countries. Environmental conditions required for the growth and development of this crop have been extensively investigated (Espinosa and Healy, 1991; Moe and Berland, 1986; Waithaka and Wanjao, 1982; Zieslin and Geller, 1983a, 1983b), but information on postharvest handling of this crop is scarce (Borochov and Keren-Paz, 1984). Providing consumers with high-quality floricultural products has become the key to success in the industry, and improving the postharvest quality of floricultural products is imperative to achieving this goal.

Flowering stems of liatris are slender with many flower heads sessile along the spike. Unlike most other spike-type flowers, liatris flowers open basipetally (Dress, 1959). In the United States, growers harvest liatris spikes when the top 2.5 to $5 \mathrm{~cm}$ of the flower heads has opened. Harvesting the spikes prematurely will not allow continuous downward opening of the flower heads and, thus, causes insufficient coloration on the spikes

Received for publication 21 Jan. 1992. Accepted for publication 1 July 1992. The cost of publishing this paper was defrayed in part by the payment of page charges. Under postal regulations, this paper therefore must be hereby marked advertisement solely to indicate this fact. for use in floral arrangements. Allowing $>5$ $\mathrm{cm}$ of flower heads to color before harvest will often result in senescing heads at the tip of the spikes and unmarketable products.

The quality and postharvest life of many cut flowers can be improved by supplying flowers with sucrose in the vase solution (Halevy and Mayak, 1979). The effects of sucrose are particularly evident when supplied to flowers that are harvested at bud stage (Mayak et al., 1973). Sucrose can be applied as pretreatment (i.e., pulsing) or as a continuous supply in the vase solution. Most flowers respond favorably to a continuous supply of sucrose in the vase solution, but the effect of pulsing varies considerably, depending on the plant species. Pulsing with high concentrations of sucrose solutions significantly improves the vase life of gladioli $[($ Gladiolus grandiflora $)=(G$. $\times$ hortu lanus Bailey)] (Mayak et al., 1973), whereas the same treatments have no effects on the postharvest performance of brodiaea (Triteleia laxa Benth.) (Han et al., 1990).

The effects of soluble sugars on postharvest performance of cut liatris were studied by Borochov and Keren-Paz (1984). They placed tight-bud stage inflorescences in solutions containing $1 \%$ or $5 \%$ sucrose for 4 days and then transferred them to solutions without sucrose. Vase life was considered terminated when the upper five flower heads 
Table 1. Effects of sucrose on the postharvest performance of Liatris spicala. Spikes were held continuously in various concentrations of sucrose or were pulsed in $10 \%$ or $20 \%$ (10\% or $20 \% \rightarrow$ 0 ) sucrose solution for $20 \mathrm{~h}$ at $24 \mathrm{C}$ and then held in solutions without sucrose. All solutions contained $200 \mathrm{mg} \mathrm{HQC} /$ liter.

\begin{tabular}{|c|c|c|c|c|}
\hline $\begin{array}{l}\text { Sucrose } \\
\text { concn } \\
(\%)\end{array}$ & $\begin{array}{c}\text { Spikes with } \\
\text { blackened } \\
\text { leaves }^{2}(\%)\end{array}$ & $\begin{array}{l}\text { Vase } \\
\text { life } \\
\text { (days) } \\
\end{array}$ & $\begin{array}{l}\text { Length of } \\
\text { inflorescence } \\
\text { showing color } \\
(\mathrm{cm})\end{array}$ & $\begin{array}{l}\text { Flower heads } \\
\text { reached anthesis } \\
(\%)\end{array}$ \\
\hline 0.0 & 100 & 6.1 & 5.1 & 27 \\
\hline 2.5 & 16.7 & 10.6 & 23.6 & 78 \\
\hline 5.0 & 0.0 & 11.8 & 28.9 & 100 \\
\hline $10 \rightarrow 0$ & 66.7 & 12.5 & 9.8 & 66 \\
\hline $20 \rightarrow 0$ & 66.7 & 12.0 & 8.4 & 53 \\
\hline \multicolumn{5}{|l|}{ Planned comparison } \\
\hline $0 \%$ vs. $(2.5 \%, 5 \%)$ & & $* *$ & $* *$ & $* *$ \\
\hline $0 \%$ vs. Pulse & & $* *$ & NS & $*$ \\
\hline$(2.5 \%, 5 \%)$ vs. Pulse & & NS & $* *$ & $*$ \\
\hline $2.5 \%$ vs. $5 \%$ & & NS & NS & NS \\
\hline
\end{tabular}

${ }^{\mathrm{z}}$ Leaf blackening was recorded 10 days after the beginning of the experiment

NS $* * *$ Nonsignificant or significant at $P=0.05$ or 0.01 , respectively.

Table 2. Effects of sucrose on the development and longevity of individual flower heads of Liatris spicata. All solutions contained $200 \mathrm{mg}$ HQC/liter.

\begin{tabular}{lcc}
\hline \hline $\begin{array}{l}\text { Sucrose } \\
\text { concn } \\
(\%)\end{array}$ & $\begin{array}{c}\text { Buds } \\
\text { opened } \\
(\%)\end{array}$ & $\begin{array}{c}\text { Longevity } \\
\text { (days) }\end{array}$ \\
\hline 0.0 & 20 & 2.1 \\
2.5 & 100 & 12.3 \\
5.0 & 100 & 12.4 \\
7.5 & 100 & 10.5 \\
10.0 & 100 & 8.8 \\
Planned comparison & & \\
$0 \%$ vs. $(2.5 \%, 5 \%$, & & \\
$7.5 \%, 10 \%)$ & $* *$ & $* *$ \\
$(2.5 \%, 5 \%)$ vs. $(7.5 \%$, & & \\
$10 \%)$ & Ns & $* *$ \\
$2.5 \%$ vs. $5 \%$ & NS & NS \\
$7.5 \%$ vs. $10 \%$ & NS & $*$ \\
$0 \%$ vs. $(2.5 \%, 5 \%)$ & $* *$ & $* *$ \\
$0 \%$ vs. $(7.5 \%, 10 \%)$ & $* *$ & $* *$ \\
\hline
\end{tabular}

NS,***Nonsignificant or significant at $P=0.05$ or 0.01 , respectively.

wilted. Pulsing stems in sucrose solutions for 4 days increased the length of the inflorescence showing color and the aesthetic value of the inflorescence, The study concluded that pulsing stems in 5\% sucrose solution improves postharvest performance of cut liatris that are harvested at the tight-bud stage. I found no reports in the literature of the effects of a continuous supply of sucrose in the vase solution on the postharvest performance of cut liatris, nor on how sucrose in vase solutions affects the development and senescence of the flower heads. This study investigated the effects of sucrose in the vase solution on the development and longevity of individual flower heads and its effects on extending the postharvest life of liatris spikes.

Plant materials. Liatris spicata corms purchased from a commercial supplier were grown in a $17 \mathrm{C}$ night temperature greenhouse at the Univ. of Massachusetts. Unless otherwise specified, spikes were harvested when the first head started to show color. They were immediately brought to the laboratory, pruned to $60 \mathrm{~cm}$ long, and the basal $10 \mathrm{~cm}$ of the leaves was removed. For vase life evaluation, individual spikes were placed in tubes containing $\approx 60 \mathrm{ml}$ of vase solution and evaluated in a room at $24 \mathrm{C}$ and illuminated with $10 \mu \mathrm{mol} \cdot \mathrm{m}^{-2} \cdot \mathrm{s}^{-1}$ cool-white fluorescent light for $24 \mathrm{~h}$. The vase life of the individual heads was considered terminated when all florets in the head had senesced. Vase life of the spike was terminated when one-third of the open flower heads had senesced.

Sucrose and development of individual flower heads. Six replicate stems were harvested at the tight-bud stage and pruned to $10 \mathrm{~cm}$ long. All flower heads but five were removed to allow a piece of stem to be placed in the vase solutions. The effects of sucrose on the development and opening of each flower head were evaluated by placing stems in solutions containing $200 \mathrm{mg}$ 8-hydroxyquinoline citrate (HQC)/liter and $0 \%$, $2.5 \%, 5 \%, 7.5 \%$, or $10 \%$ sucrose. The longevity of each flower head was determined by recording the dates when each of the flower heads reached anthesis and senescence. A flower head was considered senesced when the petaloid of all florets had wilted. The number of days between the two dates was regarded as the longevity of the flower head.

Sucrose and longevity of individualflower heads. To evaluate the effects of sucrose on the longevity of the flower heads (not on the development of the flower heads), stems were harvested at the tight-bud stage and cut to 7 $\mathrm{cm}$ long. All flower heads but the top one were removed, and the stems were placed in a solution containing 5\% sucrose with 200 mg HQC/liter. On the day of anthesis of the flower head, stems were transferred to solutions containing $200 \mathrm{mg} \mathrm{HQC/liter}$ and various concentrations of sucrose. The longevity of each flower head placed in sucrose solutions of the concentrations noted were determined. There were 10 replicates per treatment.

Sucrose and vase life of spikes. Six replicate spikes were placed continuously in solutions containing $200 \mathrm{mg} \mathrm{HQC} / \mathrm{liter}$ and $0 \%$, $2.5 \%, 5 \%, 7.5 \%$, or $10 \%$ sucrose. The vase life of each spike, length of inflorescence showing color, and the percentage of flower heads that reached anthesis were recorded.

In subsequent experiments, pulsing spikes with high concentrations of sucrose was evaluated. Spikes were pulsed 4 or $20 \mathrm{~h}$ at room temperature $(\approx 24 \mathrm{C})$ with $10 \%$ or $20 \%$ sucrose solution, then placed in $200 \mathrm{mg} \mathrm{HQC/}$ liter solution without sucrose. Vase life of these spikes were compared with those placed continuously in solutions containing $200 \mathrm{mg}$ $\mathrm{HQC} /$ liter and $0 \%, 2.5 \%$, or $5 \%$ sucrose.

Liatris spicata inflorescences are traditionally harvested from the field with the majority of the flower heads in the developing stage. Spikes used in this study contained, on the average, 100 flower heads per spike. Development of these small flower heads apparently requires carbohydrates that are supplied from the leaves and probably from reserves in the stems and corms. In cut flowers, however, carbohydrates supplied only from the leaves and stems of liatris are inadequate for the proper development of the many flower heads on each spike. Harvesting the spikes accelerated foliage senescence and blackening in liatris, and sucrose in the vase solution delayed the process (Table 1). This leaf blackening, induced by low carbohydrate conditions, was also observed in Proteas [Protea eximia (Salisb. K) Fourc], where high light conditions or girdling of the stem immediately below the inflorescence delayed or eliminated leaf blackening (Reid et al., 1989).

Without sucrose in the vase solution, only one-fourth of the flower heads reached anthesis, and the majority of those only partially opened (Table 1). The addition of $2.5 \%$ or $5 \%$ sucrose to the vase solution significantly improved the postharvest quality of the spikes. A continuous supply of sucrose $(5 \%)$ in the vase solution not only nearly doubled the vase life of the inflorescence but also increased the length of inflorescence showing color and increased the percentage of flower heads that reached anthesis. Nearly all flower heads opened when spikes were placed in solutions containing sucrose, regardless of the concentrations used in this study. The continuous development of the flower heads resulted in inflorescences with 25 to $30 \mathrm{~cm}$ of the spikes showing color.

Pulsing spikes with high concentrations of sucrose was evaluated as a potential pretreatment method for supplying sucrose to cut liatris. Ideally, the amount of sucrose absorbed during the pretreatment should be sufficient for the subsequent development of the flower heads on the spikes. Four-hour pulsing (average of 0.2 to $0.4 \mathrm{~g}$ sucrose absorbed per spike) had no advantageous effects on extending the vase life (data not shown). Pulsing for $20 \mathrm{~h}$ (1.3 to $2.1 \mathrm{~g}$ sucrose absorbed per spike) extended the vase life of spikes comparably to those placed continuously in $2.5 \%$ or $5 \%$ sucrose solutions (Table 1). Additionally, overnight pulsing increased the percentage of opened flower heads when compared with those placed in solution without sucrose. The percentage of opened flowers heads increased from $27 \%$ without sucrose to $60 \%$ with the pulsing pretreatment. Despite the average increase in length of inflorescence showing color with the pulsed treatment, statistical analysis showed no differences between the pulsed 
treatments and the control because of the great variation in the responses of each spike to the pulsed treatment. The lack of uniform responses of the spikes to the pulsed treatment can be attributed to the genetic variability of the plant materials used in the study. Spikes produced from the 1-year-old corms available commercially vary greatly in the extent of leafiness and the tightness of flower heads on the spikes. The leafiness presumably affects the volume of solution imbibed by the spikes and consequently determines the amount of sucrose absorbed during the pulsed treatment and the postharvest performance of the spikes.

In the examination of the development of each flower head in response to sucrose additions, sucrose affected the postharvest performance of liatris flower heads by influencing their ability to develop and reach anthesis and their longevity. The addition of sucrose in the solution was necessary for development and opening of all flower heads (Table 2 ). Without sucrose in the solution, only flower heads that were nearly fully developed reached anthesis, and those that opened opened only partially. These partially opened flower heads senesced rapidly, with an average longevity of 2 days. Addition of $2.5 \%$ sucrose in the vase solution was sufficient for all flower heads to fully develop and reach anthesis. This result is consistent with my findings on whole spikes that sucrose is required for the development and opening of the numerous flower heads on each spike (Table 1). Longevity of individual flower heads and vase life of spikes were similar when placed in solutions containing $2.5 \%$ or $5 \%$ sucrose (Tables 1 and 2). Concentrations of sucrose $>5 \%$, however, did significantly reduce the longevity of each flower head (Table 2).
To evaluate the effects of sucrose on the longevity of individual flower heads, spikes ( $\pm 7 \mathrm{~cm}$ long) with one tight-bud stage flower head were placed in 5\% sucrose solution until anthesis, at which time they were transferred to a vase solution containing $0 \%$ to $10 \%$ sucrose. The longevity of the flower heads was 12 days, regardless of the sucrose concentrations used. These results indicated that sucrose has limited influence on the longevity of the flower heads once they are fully developed, as was evident from the longevity of flower heads held in $0 \%$ sucrose solution. Evidently, the small amount of sucrose absorbed into the spike during the developmental period (in $5 \%$ sucrose for \pm 2 to 3 days) was sufficient for sustaining the metabolic activities and longevity of the flower heads. Complete lack of sucrose in the vase solution significantly prevented the opening and reduced the longevity of the flower heads (Table 2).

In conclusion, sucrose in the vase solution improves the keeping quality of cut liatris spikes. My study, as well as that of Borochov and Keren-Paz (1984), showed that sucrose improves the quality of cut spikes by extending their display life and increasing the length of inflorescence showing color. A continuous supply of sucrose in the vase solution resulted in $100 \%$ opening of the flower heads (Table 1). The main effect of sucrose on the vase life of liatris spikes is through its effect on the development and opening of the flower heads and to a much lesser extent on the longevity of the flower heads. The minimal effects of sucrose on the longevity of each flower head may explain the marked increase in postharvest life and quality of spikes pulsed overnight with high concentrations $(10 \%$ or $20 \%)$ of sucrose (Table 1$)$. The lack of uniform responses of spikes to the pulsed treatments is apparently due to genetic variation of the plant material and would limit its commercial application. A continuous supply of sucrose in the vase solutions can assure continuous development of the inflorescence after harvest.

\section{Literature Cited}

Borochov, A. and V. Keren-Paz. 1984. Bud opening of cut liatris flowers. Scientia Hort. 23:8589.

Dress, W.J. 1959. Notes on the cultivated Compositae. III. Liatris. Baileya 7:23-32.

Espinosa, I. and W. Healy. 1991. The role of temperature and photoperiod on Liatris spicata shoot development. J. Amer. Soc. Hort. Sci. 116(1):27-29.

Halevy, A.H. and S. Mayak. 1979. Senescence and postharvest physiology of cut flowers. I. Hort. Rev. 1:204-236.

Han, S.S., A.H. Halevy, and M.S. Reid. 1990. Postharvest handling of brodiaca flowers. HortScience 25:1268-1270.

Mayak, S., B. Bravdo, A. Guilli, and A.H. Halevy. 1973. Improvement of opening of cut gladioli flowers by pretreatment with high sucrose concentrations. Scientia Hort. 1:357-365.

Moe, R. and M. Berland. 1986. Effect of various corm treatments on flowering of Liatris spicata. Acta Hort. 177:197-201.

Reid, M.S., W. van Doorn, and J.P. Newman. 1989. Leaf blackening in Proteas. Acta Hort. 261:81-84.

Waithaka, K. and L.W. Wanjao. 1982. The effect of duration of cold treatment on growth and flowering of liatris. Scientia Hort. 18:153-158

Zieslin, N. and Z. Geller. 1983a. Studies with Liath spicata Willd. 1. Effect of temperature on sprouting, flowering and gibberellin content. Ann. Bot. 52:849-853.

Zieslin, N. and Z. Geller. 1983b. Studies with Liatris spicata Willd. 2. Effects of photoperiod on stem extension, flowering and gibberellin content. Ann. Bot. 52:855-859. 